\title{
Cadmium against Higher Plant Photosynthesis - a Variety of Effects and Where Do They Possibly Come From?
}

\author{
Zbigniew Krupa* \\ Department of Plant Physiology, Institute of Biology, Maria Curie-Skłodowska \\ University, Akademicka 19, 20-033 Lublin, Poland. Fax: (48-81) 5375102. \\ E-mail: zkrupa@biotop.umcs.lublin.pl \\ * Author for correspondence and reprint requests \\ Z. Naturforsch. 54c, 723 -729 (1999); received December 15, 1998/March 2, 1999 \\ Cadmium, Higher Plants, Photosynthesis \\ The complexity of in vivo toxic effects of $\mathrm{Cd}$ on higher plants makes almost impossible an \\ accurate distinction between direct and indirect mechanisms of its action on the photosyn- \\ thetic apparatus. We, therefore, postulate that multiple Cd effects on plant physiological and \\ metabolic processes may finally be focused on photosynthesis. This would also explain the \\ phenomenon that only a small fraction of $\mathrm{Cd}$ entering chloroplasts may cause such disastrous \\ changes in their structure and function. In return, the inhibition of photosynthesis affects \\ numerous metabolic pathways dependent on the primary carbon metabolism.
}

\section{Introduction}

The studies on the effects of Cd on photosynthesis have risen the question about the mechanisms of its toxicity towards this crucial metabolic pathway in plants. The photosynthetic apparatus appears to be especially sensitive to $\mathrm{Cd}$. On average, about $75 \%$ of $\mathrm{Cd}$ entering the plant is in one way or another bound in the root system (Jastrow and Koeppe, 1980; Krupa and Baszyński, 1995, and references therein). There are many mechanisms involved in the detoxication process giving such high efficiency of this phenomenon (Verkleij and Schat, 1990; Shier, 1994). According to available data up to $11 \%$ of total $\mathrm{Cd}$ content in plants can be found in stems, and about $15 \%$, depending on plant species and the ability to detoxicate this heavy metal, enters the leaves (Jastrow and Koeppe, 1980). Only $0.6-1.4 \%$ of this amount can be finally found in chloroplasts (Weigel and Jäger, 1980; Krupa and Baszyński, 1995; Leita et al., 1996). This fact might be surprising in the light of the data mentioned above. How to explain that only a very small fraction of all $\mathrm{Cd}$ entering leaf tissues is located in these organelles? Very recently, Chardonnens et al. (1998) reported that in leaves of both Cd tolerant and sensitive ecotypes of Silene vulgaris the highest metal concentration was found in lower epidermis, whilst mesophyll cells were the region of its relatively lowest accumulation.

The analysis of an average $\mathrm{Cd}$ accumulation within the mesophyll cells reveals that about $48 \%$ is located in the cell wall, $39 \%$ in the cytoplasm and vacuole and only $13 \%$ in chloroplasts and mitochondria (Ernst, 1980). Although the contents of $\mathrm{Cd}$ in chloroplast stroma and thylakoids are not known, we may suppose that they must be much lower since in many cases metal may form deposits on the outer surface of the chloroplast envelope (Cumming and Taylor, 1990). Therefore, facing the above data on metal accumulation in specific plant organs and organelles one may ask for the reasons of such high susceptibility of photosynthesis to $\mathrm{Cd}$.

\section{The principles of in vitro and in vivo studies on Cd effects on photosynthesis}

It was first in 1949 when Macdowall observed a strong inhibition of photosystem II activity by $\mathrm{Hg}$ and $\mathrm{Cu}$ in isolated chloroplasts, and no effect of Ni, Co and Zn (Macdowall, 1949). And then, after many years of a lag phase the studies on the effects of heavy metals, including $\mathrm{Cd}$, have emerged again in the early seventies. The research on the inhibitory effects of $\mathrm{Cd}$ and other heavy metals on the photosynthetic apparatus was at that time mostly concentrated on thylakoid membranes and the components of photosynthetic electron transport, located mainly within these membranes. Although all those experiments have brought numerous valuable data, they were mostly concentrated on in vitro studies, i.e. isolated cells, protoplasts or chloroplasts and their fragments like thylakoids. 
The major disadvantage of such studies is that the time of the metal action must be very short due to very poor object vitality, usually counted in hours. Thus, to achieve distinct inhibitory effects enormously high metal concentrations were used, up to 1000 times higher than those for in vivo studies. Moreover, one must realize that the in vitro system lacks the whole organism responses to this stressful situation, therefore observed phenomena are of rather simple and direct nature. Although the results of in vivo experiments on the whole plant level are much more complicated to explain because of rather indirect effects of $\mathrm{Cd}$ on the photosynthetic apparatus, mostly due to the complexity of treated system, they have certain advantages over in vitro studies. First of all, much lower metal concentrations are used, then the treatment can be prolonged to days and/or weeks. This laboratory situation is, therefore, much closer to naturally Cd-polluted environment than in vitro ones. However, we must keep in mind that the full picture can only be obtained after careful analysis of the results of both experimental approaches to the problem of Cd toxicity towards the photosynthetic apparatus of higher plants.

The age of plants exposed to Cd treatment is also of crucial importance. The effects of $\mathrm{Cd}$ on plant as a whole and photosynthesis as such differ very substantially due to the stage of growth. In very young seedlings being in intial growth stage and treated shortly with $\mathrm{Cd}$ we can only observe retarded growth with no spectacular effects of the metal on the photosynthetic apparatus. In young plants subjected to short-term (days) treatment with $\mathrm{Cd}$, despite the retarded growth, a decrease in plastid pigments and rather indirect inhibition of photosynthetic electron transport can be observed (Skórzyńska-Polit and Baszyński, 1995, 1997). Under such experimental conditions Cd also interacts with the uptake of essential nutritional elements like for instance $\mathrm{Fe}, \mathrm{Ca}, \mathrm{P}, \mathrm{Mg}, \mathrm{Mn}$ and many others (Siedlecka, 1995, and references therein; Hernández et al., 1996; Yang et al., 1996). If plants are older and treated with $\mathrm{Cd}$ for weeks then the most important effect of metal toxicity is the strong interaction with essential elements with all consecutive consequences for plant growth and metabolism. The observed degradation of the photosynthetic apparatus reflects the premature senescence processes initiated by $\mathrm{Cd}$ (Krupa and
Baszyński, 1995). Some of these phenomena will be discussed in more details in the following chapters.

\section{Cd versus photosynthetic electron transport}

The results of in vitro and in vivo experiments on the effects of $\mathrm{Cd}$ on isolated chloroplasts or thylakoid membranes are summarized in Fig. 1. There are several steps in the photosynthetic electron transport chain found to be affected directly or indirectly by Cd (Krupa and Baszyński, 1995; Prasad, 1995, 1996, and references therein). One of the most crucial chlorophyll-protein complexes - light-harvesting chlorophyll $a / b$ protein complex II (LHCII), the major light harvesting antenna in photosynthesis, was shown to be disturbed by $\mathrm{Cd}$ in at least two aspects of its structure and function. First, the oligomeric structure of this complex, which is of primary importance for the efficient collection of light energy, is indirectly affected by $\mathrm{Cd}$. Metal causes a decrease in the level of trans $-\Delta^{3}$-hexadecenoic fatty acid, specifically bound in $s n-2$ position of the chloroplastic phosphatidylglycerol (PG) molecules (Krupa, 1988). The level of this fatty acid has been proven to be correlated with oligomerization of LHCII (Krupa,

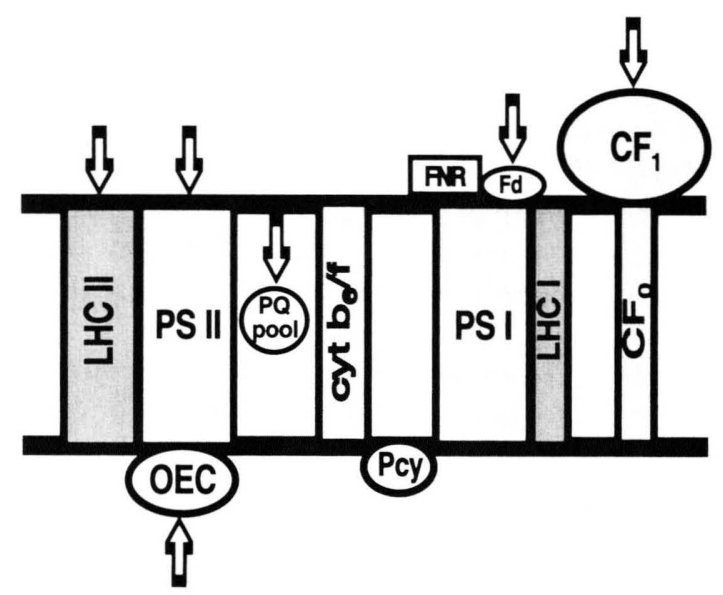

Fig. 1. The toxicity of Cd towards components of the photosynthetic electron transport. Arrows indicate sites of the metal action. $\mathrm{CF}_{0}$, proton channel complex; $\mathrm{CF}_{1}$, chloroplast ATP synthase complex; cyt $b_{6} / f$, cytochrome $b_{6} / f$ complex; Fd, ferredoxin; FNR, ferredoxin-NADP oxidoreductase; LHCI, light-harvesting complex of photosystem I; LHCII, light-harvesting complex of photosystem II; OEC, oxygen-evolving complex; Pcy, plastocyanin; PQ, plastoquinone; PSI, photosystem I; PSII, photosystem II. 
1988; Krupa et al., 1992b). Degradation of LHCII oligomeric structure leads to less efficient light energy utilization and decreased rate of photosynthetic electron transport. Also other authors reported that $\mathrm{Cd}$ interacts in vitro with the subunits of this complex leading to its conformational changes (Ahmed and Tajmir-Riahi, 1993). Moreover, we must consider the fact that LHCII comprises up to $70 \%$ of the total chlorophyll content in thylakoid membranes. Thus, the inhibitory effects of $\mathrm{Cd}$ on certain steps of chlorophyll synthesis must also be reflected in this complex. Besides Stobart's studies (1985) revealing that Cd may affect both the formation of $\delta$-aminolevulinic acid (ALA) and the photoreduction of protochlorophyllide, it was also Böddi et al. (1995) who has observed the inhibition of the latter step of chlorophyll synthesis. The opposite conclusion was drawn by Horváth et al. (1996) from the studies on the effects of $\mathrm{Cd}$ on the formation of the photosynthetic apparatus during greening of barley leaves. According to them, Cd acts mainly by disturbing the integration of chlorophyll into stable chlorophyll-protein complexes of the thylakoid membranes rather than affecting chlorophyll synthesis itself.

The numerous studies on the effects of $\mathrm{Cd}$ on the photosystem II (PSII) have proven it to be especially sensitive to the metal, both on its donor and acceptor side (Clijsters and Van Assche, 1985; Van Assche and Clijsters, 1990; Krupa and Baszyński, 1995; Prasad, 1995, 1996, and references therein). Oxygen evolving complex (OEC), donating electrons from the thylakoid lumen straight to the PSII reaction centre, was postulated as the primary target of Cd toxicity. Both the destruction of OEC and the interaction with ions like $\mathrm{Mn}^{2+}, \mathrm{Ca}^{2+}$ and $\mathrm{Cl}^{-}$, neccessary for its proper function, have been considered as mechanisms of this toxicity (Maksymiec and Baszyński, 1988; Skórzyńska and Baszyński, 1993). Also the PSII reaction centre with all its redox components may be affected by Cd (Baszyński et al., 1980; Barua and Jana, 1986; Becceril et al., 1988; Atal et al., 1991; Tukendorf and Baszyński, 1991). However, these data were mostly obtained from in vitro studies on isolated chloroplasts, thylakoids or purified PSII particles and cannot be directly discussed in terms of whole plant level. The total plastoquinone (PQ) pool is also decreased by $\mathrm{Cd}$, thus certainly leading to less efficient transport of electrons to the photosystem I (PSI) (Baszyński et al., 1980). This photosystem, being for long time considered as relatively resistant to $\mathrm{Cd}$, has also appeared to be affected by the metal, although in a rather indirect way. Siedlecka and Baszyński (1993) showed that in Cd-treated maize seedlings the inhibition of electron flow via PSI is due to Cd-induced Fe deficiency, and thus, significantly diminished level and activity of ferredoxin (Fd).

Since there are almost no reports on direct influence of $\mathrm{Cd}$ on the photophosphorylation components in thylakoid membranes, except that of Teige et al. (1990), we may only speculate that the inhibition of the electron flow must have an indirect impact on this process as well.

\section{Toxicity of Cd towards dark reactions of photosynthesis}

In 1985 Weigel, after presenting his results on in vitro effects of $\mathrm{Cd}$ on photosynthetic reactions in isolated mesophyll protoplasts, has concluded that: "... the present results leave little doubt that $C d$ acts on the photosynthetic apparatus mainly at the level of dark reactions but not on membrane bound, primary photochemical reactions" (Weigel, 1985). A few years later a similar conclusion has been drawn from chlorophyll $a$ fluorescence studies, carried out in vivo on bean plants (Krupa et al., 1992a, 1993). Therefore, can we really ascribe all the inhibitory effects of $\mathrm{Cd}$ to the photosynthetic carbon reduction cycle, considering observed changes in the primary photochemical reactions and electron transport as a secondary effects?

As it has been already shown both in case of $\mathrm{Cd}$, as of many other heavy metals, all three key steps of the Calvin cycle - carboxylation, reduction and regeneration, are heavily affected (Krupa and Baszyński, 1995; Prasad, 1995, 1996, and references therein). Without any doubt, the most sensitive step of the enzymatic phase of photosynthesis is the carboxylation of the primary acceptor of $\mathrm{CO}_{2}$ - ribulose-1,5-bisphosphate (RuBP) as well as phosphoenolpyruvate (PEP). Both enzymes controlling these reactions in $\mathrm{C}_{3}$ and $\mathrm{C}_{4}$ plants Rubisco and PEP carboxylase, are inhibited by $\mathrm{Cd}$ (Krupa and Baszyński, 1995; Prasad, 1995, and references therein). It is actually considered that $\mathrm{Cd}$ may affect Rubisco function and structure in sev- 
eral ways, depending on the metal concentration in the nutrient medium, plant growth stage and eventually plant suceptibility to heavy metal. The nature of this inhibition is not fully elucidated yet, although there are some suppositions presented very recently by Siedlecka et al. (1998). Fig. 2 shows that $\mathrm{Cd}$ may decrease enzyme activity by damaging its protein structure, may replace $\mathrm{Mg}^{2+}$ ions being neccessary cofactors of the carboxylation reaction, or may even cause shift towards oxygenation properties of Rubisco. Very high concentrations of $\mathrm{Cd}$ may also lead to an irreversible disconnection of small and large subunits of the enzyme causing its full inhibition. The latter was observed only in in vitro experiments (Stiborova, 1988; Malik et al., 1992). The list of enzymes involved in the primary carbon metabolism and affected by Cd comprises also of 3-phosphoglyceric acid kinase, glyceraldehyde-3-phosphate dehydrogenase, ribulose-5-phosphate kinase, fructose-1,6bisphosphatase, aldolase, fructose-6-phosphate, 2kinase and very recently investigated bean chloroplast carbonic anhydrase (Krupa and Baszyński, 1995, and references therein; Siedlecka et al., 1997, 1998).

It is, therefore, clear that the dark phase of photosynthesis is very heavily affected by $\mathrm{Cd}$. Thus, we may now come back to the question asked at the beginning of this chapter. What is the primary and the secondary target of Cd toxicity towards photosynthesis - electron transport or enzymatic reactions? As shown recently in our laboratory, the Calvin cycle is the primary target, although the plant growth stage must be also considered. In older plants treated with $\mathrm{Cd}$ for longer periods of time the substantial direct effects of heavy metal

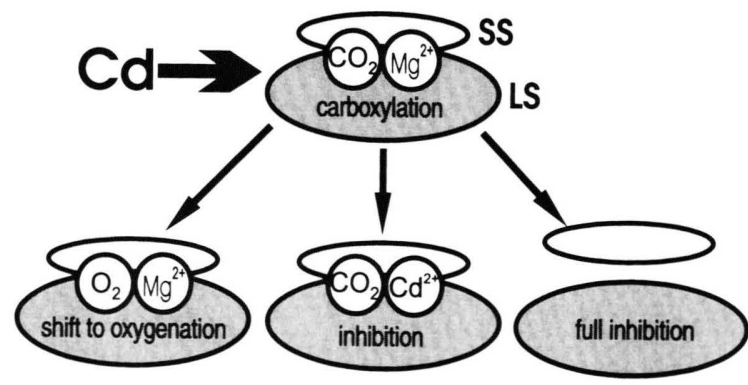

Fig. 2. The effects of $\mathrm{Cd}$ on the function and structure of ribulose-bisphosphate carboxylase/oxygenase (Rubisco). LS, large subunits of Rubisco; SS, small subunits of Rubisco (after Siedlecka et al. 1998). on the components of photosynthetic electron transport are observed (Siedlecka and Krupa, 1996b; Skórzyńska-Polit et al., 1995; SkórzyńskaPolit and Baszyński 1995, 1997; Krupa and Moniak, 1998). In general, our previous hypothesis is supported that the primary target of heavy metal toxicity, including $\mathrm{Cd}$, might be the enzymatic phase of photosynthesis, which in return may slow down the reactions of the light phase, either by down-regulation or by feedback inhibition due to inefficient consumption of ATP and NADPH, thus the maintenance of a high proton gradient across the thylakoid membrane (Krupa et al., 1993).

\section{Direct or indirect mechanisms of $\mathrm{Cd}$ toxicity for the photosynthetic apparatus?}

Before we shall try to answer this question we must realize all the complexity of the higher plant. $\mathrm{Cd}$, as well as other heavy metals, affects higher plant organism on many levels of its organization and function. There are no single, isolated reactions or pathways or processes being totally independent from each other. A simple and obvious example is shown in Fig. 3. The portion of total higher plant metabolism that aquires carbon atoms from atmospheric $\mathrm{CO}_{2}$ and incorporates them into the organism is photosynthesis. It converts atmospheric $\mathrm{CO}_{2}$ and the sunlight energy into organic compounds with the release of $\mathrm{O}_{2}$. These compounds are then "burned" in cellular respiration, converting them and $\mathrm{O}_{2}$ into $\mathrm{CO}_{2}$ and chemical energy (ATP). Therefore, any disturbance in one of these interrelated processes affects the other one. One may easily conclude that the

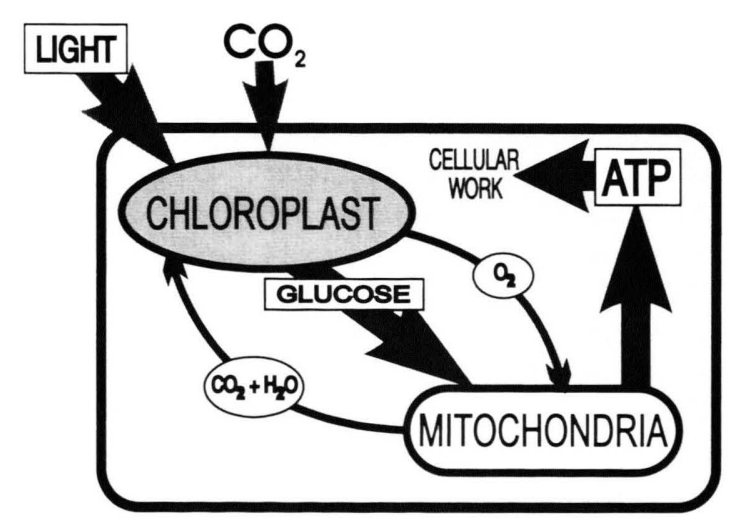

Fig. 3. An example of the intercellular relationships between key metabolic processes. 
more general physiological or metabolic function is affected by heavy metal the wider is the response of anatomical structures, cell compartments or processes within the higher plant.

In the opinion of many authors water stress and abnormalities observed in plant gas exchange are the primary reasons for all other disturbances caused by Cd (Barceló and Poschenrieder, 1990; Costa and Morel, 1994; Costa et al., 1994; Leita et al., 1995). We cannot forget that also plant hormones, regulating most of its physiological and metabolic processes, are influenced by $\mathrm{Cd}$ as well as many phenomena related to plant gene expression and translation (Moya et al., 1995; Shah and Dubey, 1995; Hollenbach et al., 1997).

As we have already mentioned in the previous chapters, there are also strong indications that $\mathrm{Cd}$ initiates the premature senescence of plants. One of striking visual symptoms is the degradation of the lamellar structure of chloroplasts in Cd-treated plants with all the consequences for the structure and function of photosynthetic electron transport (Baszyński et al., 1980; Krupa et al., 1987; Barceló et al., 1988; Ghoshroy and Nadakavukaren, 1990).

The most visible symptom of Cd toxicity is leaf chlorosis. There are two major reasons of chlorosis, both already mentioned in earlier chapters. One is inhibition of chlorophyll synthesis and the other - interaction between Cd and Fe (Siedlecka and Krupa, 1996a). Cd-induced Fe deficiency may also affect photosynthetic electron transport and the Calvin cycle activity (Siedlecka and Baszyński, 1993; Siedlecka et al., 1996, 1997).

Ahmed A. and Tajmir-Riahi H. A. (1993), Interaction of toxic metal ions $\mathrm{Cd}^{2+}, \mathrm{Hg}^{2+}$ and $\mathrm{Pb}^{2+}$ with lightharvesting proteins of chloroplast thylakoid membranes. An FTIR studies. J. Inorg. Chem. 50, 235-243.

Atal N., Saradhi P. P. and Mohanty P. (1991), Inhibition of the chloroplast photochemical reactions by treatment of wheat seedlings with low concentrations of cadmium: analysis of electron transport activities and changes in fluorescence yield. Plant Cell Physiol. 32, 943-951.

Barua B. and Jana S. (1988), Effects of heavy metals on dark induced changes in Hill reaction activity, chlorophyll and protein contents, dry matter and tissue permeability. Photosynthetica 20, 74-76.

Barceló J. and Poschenrieder C. (1990), Plant water relations as affected by heavy metal stress: a review. J. Plant Nutr. 13, 1-37.
The complexity and diversity of in vivo toxic effects of $\mathrm{Cd}$ on higher plant makes an accurate distinction between direct and indirect mechanism of its action almost impossible. We, therefore, postulate, that in fact we deal with multiple effects which are finally focused on the photosynthetic apparatus. On the other hand, photosynthesis being absolutely crucial for the functioning of plant, may in return affect all other physiological and metabolic processes.

\section{Acknowledgements}

This short review is to a great extent a summary of the results of our many years' research on the effects of $\mathrm{Cd}$ on photosynthesis, carried out in the Department of Plant Physiology, Maria CurieSkłodowska University, Lublin, Poland and is dedicated to Professor Tadeusz Baszyński, a longterm head of this Department, an initiator of the studies on the effects of heavy metals on photosynthesis, our mentor and friend.

The author also wishes to thank Professor Gábor Horváth for his kind invitation to have a plenary lecture on the International Workshop on Stress Synergism in Plants - Biotic and Abiotic Stress in Photosynthesis, held in Tata, Hungary, in August 1998. This review is a written version of this lecture.

The financial assistance of the Polish Committee for Scientific Research, grant 6P04C.064.15 in the course of preparing this review is gratefully acknowledged.

Barceló J., Vázquez M. D. and Poschenrieder C. (1988), Structural and ultrastructural disorders in cadmiumtreated bush bean plants (Phaseolus vulgaris L.). New Phytol. 108, 37-49.

Baszyński T., Wajda L., Król M., Wolińska D., Krupa Z. and Tukendorf A. (1980), Photosynthetic activities of cadmium-treated tomato plants. Physiol. Plant. 48, $365-370$.

Becceril J. M., MuÍoz-Rueda A., Aparicio-Tejo P. and Gonzales-Murua C. (1988), The effects of cadmium and lead on photosynthetic electron transport in clover and lucerne. Plant Physiol. Biochem. 26, 357-363.

Böddi B., Oravecz A. R. and Lehoczki E. (1995), Effect of cadmium on organization and photoreduction of protochlorophyllide in dark-grown leaves and etioplasts of inner membrane preparations of wheat. Photosynthetica 31, 411-420. 
Chardonnens A. N., ten Bookum W. M., Kuijper L. D. J., Verkleij J. A. C., and Ernst W. H. O. (1998), Distribution of cadmium in leaves of cadmium tolerant and sensitive ecotypes of Silene vulgaris. Physiol. Plant. 104, $75-80$.

Clijsters H. and Van Assche F. (1985), Inhibition of photosynthesis by heavy metals. Photosynth. Res. 7, 31 40.

Costa G. and Morel J. L. (1994), Water relations, gas exchange and amino acid content in Cd-treated lettuce. Plant Physiol. Biochem. 32, 561-570.

Costa G., Michaut J. C. and Morel J. L. (1994), Influence of cadmium on water relations and gas exchanges, in phosphorus deficient Lupinus albus. Plant Physiol. Biochem. 32, 105-114.

Cumming J. R. and Taylor G. J. (1990), Mechanisms of metal tolerance in plants: physiological adaptations for exclusion of metal ions from the cytoplasm, in: Stress Responses in Plants: Adaptation and Acclimation Mechanisms (R. G. Alscher and J. R. Cumming, eds.), Wiley-Liss, New York, 329-356.

Ernst W. H. O. (1980), Biochemical aspects of cadmium in plants, in: Cadmium in the Environment. Part I: Ecological Cycling (J. O. Nriagu, ed.), John Wiley and Sons, New York, 639-653.

Ghoshroy S. and Nadakavukaren M. J. (1990), Influence of cadmium on the ultrastructure of developing chloroplasts in soybean and corn. Environ. Exp. Bot. 33, $187-192$.

Hernández L. E., Ramos I., Carpena-Ruiz R., Lucena J. J. and Gárate A. (1996), Effect of cadmium on the distribution of micronutrients in Lactuca spp., maize and pea plants. In: Fertilizers and Environment (C. Rodriguez-Barneco, ed.). Kluwer Academic Publishers, Dordrecht, 503-508.

Hollenbach B., Schreiber L., Hartung W. and Dietz K. J. (1997), Cadmium leads to stimulated expression of the lipid transfer protein genes in barley: implications for the involvement of lipid transfer proteins in wax assembly. Planta 203, 9-19.

Horváth G., Droppa M., Oravecz A., Raskin V. I. and Marder J. B. (1996), Formation of the photosynthetic apparatus during greening of cadmium-poisoned barley leaves. Planta 199, 238-243.

Jastrow J. and Koeppe D. E. (1980), Uptake and effects of cadmium in higher plants. In: Cadmium in the Environment. Part I: Ecological Cycling (J. O. Nriagu, ed.). John Wiley and Sons, New York, 608-638.

Krupa Z. (1988), Cadmium-induced changes in the composition and structure of the light-harvesting chlorophyll $a / b$ protein complex. Physiol. Plant. 73, 518-524.

Krupa Z. and Baszyński T. (1995), Some aspects of heavy metal toxicity towards photosynthetic apparatus - direct and indirect effects on light and dark reactions. Acta Physiol. Plant. 17, 177-190.

Krupa Z. and Moniak M. (1998), The stage of leaf maturity implicates the response of the photosynthetic apparatus to cadmium toxicity. Plant Sci. 138, 149-156.

Krupa Z., Skórzyńska E., Maksymiec W. and Baszyński T. (1987), Effect of cadmium treatment on the photosynthetic apparatus and its photochemical activities in greening radish seedlings. Photosynthetica 21, 156164.

Krupa Z., Öquist G. and Huner N. P. A., (1992a), The influence of cadmium on primary photosystem II pho- tochemistry as revealed by chlorophyll $a$ fluorescence - a preliminary study. Acta Physiol. Plant. 14, $71-76$.

Krupa Z., Williams J. P., Khan M. U. and Huner N. P. A. (1992b), The role of acyl lipids in reconstitution of lipid-depleted light harvesting complex from cold-hardened and non-hardened rye. Plant Physiol. 100, 931-938.

Krupa Z., Öquist G. and Huner N. P. A., (1993), The effects of cadmium on photosynthesis of Phaseolus vulgaris - a fluorescence analysis. Physiol. Plant. 88, $626-630$.

Leita L., Marchiol L., Martin M., Peressotti A., Delle Vedove G. and Zerbi G. (1995), Transpiration dynamics in cadmium-treated soybean (Glycine max L.) plants. J. Agron. Crop Sci. 175, 153-156.

Leita L., De Nobili M., Cesco S. and Mondini C. (1996), Analysis of intercellular cadmium forms in roots and leaves of bush bean. J. Plant Nutr. 19, 527-533.

Macdowall F. D. H. (1949), The effects of some inhibitors of photosynthesis upon the photochemical reduction of a dye by isolated chloroplasts. Plant Physiol. 24, $462-480$.

Maksymiec W. and Baszyński T. (1988), The effect of $\mathrm{Cd}^{2+}$ on the release of proteins from thylakoid membranes of tomato leaves. Acta Soc. Bot. Pol. 57, 465-474.

Malik D., Sheoran I. S. and Singh R. (1992), Carbon metabolism in leaves of cadmium treated wheat seedlings. Plant Physiol. Biochem. 30, 223-229.

Moya J. L., Ros R. and Picazo I. (1995), Heavy metalhormone interactions in rice plants: effects on growth, net photosynthesis, and carbohydrate distribution. J. Plant Growth Regul. 14, 61-67.

Prasad M. N. V. (1995), Cadmium toxicity and tolerance in vascular plants. Environm. Exp. Bot. 35, 525-545.

Prasad M. N. V. (1996), Trace metals. In: Plant Ecophysiology (M. N. V. Prasad, ed.). John Wiley and Sons, New York, 207-249.

Shah K. and Dubey R. S. (1995), Effect of cadmium on RNA level as well as activity and molecular forms of ribonuclease in growing rice seedlings. Plant Physiol. Biochem. 35, 577-584.

Shier W. T. (1994), Metals as toxins in plants. J. Toxicol.Toxin Rev. 13, 205-216.

Siedlecka A. (1995), Some aspects of interactions between heavy metals and plant mineral nutrients. Acta Soc. Bot. Pol. 64, 265-272.

Siedlecka A. and Baszyński T. (1993), Inhibition of electron flow around photosystem I in chloroplasts of Cdtreated maize plants is due to Cd-induced iron deficiency. Physiol. Plant. 87, 199-202.

Siedlecka A. and Krupa Z. (1996a), Interaction between cadmium and iron. Accumulation and distribution of metals and changes in growth parameters of Phaseolus vulgaris L. seedlings. Acta Soc.Bot. Pol. 66, $1-6$.

Siedlecka A. and Krupa Z. (1996b), Interaction between cadmium and iron and its effects on photosynthetic capacity of primary leaves of Phaseolus vulgaris. Plant Physiol. Biochem. 34, 833-841.

Siedlecka A., Krupa Z., Samuelsson G., Öquist G. and Gardeström P. (1997), Primary carbon metabolism in Phaseolus vulgaris plants under $\mathrm{Cd} / \mathrm{Fe}$ interaction. Plant Physiol. Biochem. 35, 951 - 957. 
Siedlecka A., Samuelsson G., Gardeström P., Kleczkowski L. A. and Krupa Z. (1998), The "activatory model" of plant response to moderate cadmium stress - relationship between carbonic anhydrase and Rubisco. In: Photosynthesis: Mechanisms and Effects (G. Garab, ed.). Kluwer Academic Publishers, Dordrecht-Boston-London, 2677-2680.

Skórzyńska E. and Baszyński T. (1993), The changes in PSII complex polypeptides under cadmium treatment - are they of direct or indirect nature? Acta Physiol. Plant. 15, 263-269.

Skórzyńska-Polit E. and Baszyński T. (1995), Photochemical activity of primary leaves in cadmiumstressed Phaseolus coccineus depends on their growth stages. Acta Soc. Bot. Pol. 64, 273-279.

Skórzyńska-Polit E. and Baszyński T. (1997), Differences in sensitivity ot the photosynthetic apparatus in $\mathrm{Cd}$-stressed runner bean plants in relation to their age. Plant Sci. 128, 11-21.

Skórzyńska-Polit E., Bednara J. and Baszyński T. (1995), Some aspects of runner bean plant response to cadmium at different stages of the primary leaf growth. Acta Soc. Bot. Pol. 64, 165-170.

Stiborova M. (1988), $\mathrm{Cd}^{2+}$ ions affect the quarternary structure of ribulose-1,5-bisphosphate carboxylase from barley leaves. Biochem. Physiol. Pflanzen 183, $371-378$.

Stobart A. K., Gffiths W. T., Ameen-Bukhari I. and Sherwood R. P. (1985), The effects of $\mathrm{Cd}^{2+}$ on the biosynthesis of chlorophyll in leaves of barley. Physiol. Plant. 63, 293-298.
Teige M., Huchzermeyer B. and Schultz G. (1990). Inhibition of chloroplast ATPsynthase/ATPase is a primary effect of heavy metal toxicity in spinach plants. Biochem. Physiol. Pflanzen 186, 165-168.

Tukendorf A. and Baszyński T. (1991), The in vivo effect of cadmium on photochemical activities in chloroplasts of runner bean plants. Acta Physiol. Plant. 13, $51-57$.

Van Assche F. and Clijsters H. (1990), Effects of metals on enzyme activity in plants. Plant Cell. Environ. 13, $195-206$

Verkleij J. A. C. and Schat H. (1990), Mechanisms of metal tolerance in higher plants, in: Heavy Metal Tolerance in Plants: Evolutionary Aspects (A. J. Shaw, ed.), CRC Press Inc., Boca Raton, 179-193.

Weigel H. J. (1985), The effect of $\mathrm{Cd}^{2+}$ on photosynthetic reactions of mesophyll protoplasts. Physiol. Plant. 63, $192-200$

Weigel H. J. and Jäger H. J. (1980), Subcellular distribution and chemical form of cadmium in bean plants. Plant Physiol. 65, 480-482.

Yang X., Baligar V. C., Martens D. C. and Clark R. B. (1996), Cadmium effects on influx and transport of mineral nutrients in plant species. J. Plant Nutr. 19, $643-656$. 